\title{
PENERAPAN MODEL PEMBELAJARAN DISCOVERY LEARNING DI MTS. MUHAMMADIYAH 22 PADANGSIDIMPUAN
}

\author{
Ramos Hidayat Sitompul, S. Pd \\ Alumni Fakultas Agama Islam Universitas Muhammadiyah Tapanuli Selatan
}

\begin{abstract}
In the process of learning History of Islamic Culture, there are various kinds of learning models that can be applied. Most teachers in these subjects mostly use lecture and discussion methods. However, this method is sometimes constrained by time allocation which is very difficult to create material that will be taught in accordance with the planned in karnakan material of history of Islamic culture which is solid with the number of learners which is relatively many.
\end{abstract}

Discovery Learning method is widely selected Master in MTs. Muhammadiyah 22 in the process of learning. One of them on the history of Islamic culture. Hopefully with this method, it can help Teachers explain the learning materials appropriately, students can also interact with each other, ask each other in groups that have been set.

Keywords: Implementation, Learning Model, Discovery Learning

\section{A. PENDAHULUAN}

Pendidikan selalu berkenaan dengan upaya pembinaan manusia, sehingga suatu keberhasilan sangat tergantung pada unsur manusianya yaitu guru sebagai ujung tombak pendidikan karena guru secara langsung berupaya mempengaruhi, membina dan mengembangkan kemampuan siswa agar menjadi manusia yang cerdas, terampil dan bermoral tinggi. Sebagai ujung tombak di dalam proses belajar mengajar, guru dituntut mampu menguasai materi agar siswa dapat berpikir secara kreatif. Sebagai orang yang kreatif, guru menyadari bahwa kreativitas merupakan universal dan oleh karenanya semua kegiatannya ditopang, dibimbing dan dibangkitkan oleh kesadaran itu. Sesuai dengan kebutuhan setiap siswa pendidikan agama wajib ada pada setiap jenjang pendidikan.

Berbagai usaha telah dilakukan pemerintah untuk menciptakan sumber daya manusia yang diharapkan untuk meningkatkan kualitas pendidikan. Usaha pemerintah dalam mencapai tujuan pendidikan terwujud melalui penyempurnaan 
kurikulum setiap periode waktu tertentu, seperti kurikulum 1994, Kurikulum Berbasis Kompetensi (KBK), Kurikulum Tingkat Satuan Pendidikan (KTSP) dan Kurikulum 2013 sebagai penyempurna dari kurikulum sebelumnya. Usaha untuk meningkatkan kualitas guru dan tenaga pendidik diselenggarakan penataran, Musyawarah Guru Mata Pelajaran (MGMP) di setiap kota serta sertifikasi guru. Kurikulum 2013 telah diperkenalkan oleh pemerintah melalui sertifikasi guru. Pada kurikulum 2013 ini guru dibekali dengan bahan ajar yang terdiri dari bahan ajar guru dan bahan ajar siswa, sehingga guru dapat mengembangkan perangkat pembelajaran yang mampu menunjang keberhasilan dalam proses pembelajaran. ${ }^{1}$

Kenyataan yang terjadi dalam kegiatan belajar mengajar yang berlangsung di Madrasah Tsanawiyah 22 Padangsidimpuan melalui kegiatan wawancara pada tanggal 20 September dengan ibu Nurhajji Sijabat ${ }^{2}$ sebagai guru mata pelajaran Sejarah Kebudayaan Islam di Madrasah Tsanawiyah Muhammadiyah 22 Padangsidimpuan belum sesuai dengan apa yang diharapkan. Pembelajaran yang terjadi monoton, kurang tepatnya model pembelajaran yang diterapkan oleh guru Sejarah Kebudayaan Islam sehingga siswa tidak termotivasi untuk belajar. Proses pembelajaran masih terpusat kepada guru (teacher center) dengan menggunakan metode yang kurang tepat terlihat bahwa guru belum menciptakan pemahaman dan pengertian yang diharapkan pada materi pembelajaran. Guru masih kurang kreatif menciptakan suasana pembelajaran yang menarik. Guru masih kurang mampu mengembangkan potensi intelektual siswa. Guru belum menerapkan metode belajar menemukan sesuatu. Guru masih kurang mampu menciptakan pembelajaran yang membuat ingatan siswa lebih tahan lama, masih kurang mampu melatih keterampilan siswa memecahkan masalah/persoalan sendiri dan kurang mampu melatih siswa untuk dapat mengumpulkan dan menganalisis data sendiri sehingga siswa masih takut mengekspesikan dirinya, bahkan untuk menyampaikan sesuatu yang sudah di ketahuinya terasa sangat berat yang berdampak pada hasil belajar yang rendah.

\footnotetext{
${ }^{1}$ Kemendikbud, Modul Pelatihan Implementasi Kurikulum 2013, (Jakarta, Badan Pengembangan Sumber Daya Manusia Pendidikan dan Kebudayaan dan Penjamin Mutu Pendidikan,2014), hlm 87-100

${ }^{2}$ Guru mata pelajaran sejarah kebudayaan Islam, di MTs. Muhammadiyah 22 Padangsidimpuan
} 
Salah satu model pembelajaran yang memiliki tujuan yang sesuai dengan harapan yang telah peneliti sampaikan di atas adalah model pembelajaran Discovery Learning, karena dengan menggunakan Discovery Learning dapat merubah kondisi belajar belajar yang pasif menjadi aktif, merubah pembelajaran yang Teacher Center ke Student Center dan merubah modus siswa yang menerima informasi secara keseluruhan dari guru ( Ekspository) ke modus siswa yang menemukan informasi sendiri ( Discovery) ${ }^{3}$

Model Discovery Learning adalah model pembelajaran dimana guru memberikan kebebasan siswa untuk menemukan sesuatu sendiri karena dengan menemukan sendiri siswa dapat lebih mengerti secara mendalam. Dengan menggunakan model pembelajaran penemuan (Discovery Learning), peneliti berharap dapat meningkatkan aktivitas dan kompetensi belajar siswa sehingga masalah yang peneliti temukan mendapat solusi. Penggunaan Discovery Learning ini akan disertai dengan Lembar Kerja Siswa (LKS) karena dengan adanya LKS siswa akan bekerja lebih terarah. LKS merupakan sebuah bahan ajar dimana di dalamnya terdapat tugas-tugas yang disusun dengan terstruktur dan harus dikerjakan oleh siswa.

Berdasarkan uraian diatas, peneliti merasa perlu menggunakan model pembelajaran yang efektif, model pembelajaran yang mengaktifkan siswa agar proses belajar tidak berpusat kepada guru sehingga siswa dapat menemukan sendiri konsep-konsep materi pembelajaran. Oleh karena itu dirasa perlu diadakan penelitian tentang 'Penerapan Model Pembelajaran Discovery Learning di MTs. Muhammadiyah 22 Padangsidimpuan.

\section{B. Tujuan Penelitian}

Berdasarkan rumusan masalah penelitian ini bertujuan untuk:

1. Mengetahui bagaimana penerapan model Discovery Leraning untuk meningkatkan hasil belajar Sejarah Kebudayan Islam di kelas VIIb MTs. Muhammadiyah 22 Padangsidimpuan.

\footnotetext{
${ }^{3}$ kemendikbud, 2014. Hal 37.
} 
2. Mengetahui apakah penerapan Discovery Leraning dapat mengaktipkan siswa dalam belajar Sejarah kebudayaan Islam di kelas VIIb MTs. Muhammadiyah 22 Padangsidimpuan.

\section{KERANGKA TEORITIS}

\section{Pengertian Belajar}

Belajar merupakan suatu proses yang dilakukan seserorang untuk memperoleh pengalaman dan merubah tingkah laku. Trianto mendefenisikan belajar adalah proses menciptakan hubungan antara sesuatu (pengetahuan) yang sudah dipahami dan sesuatu (pengetahuan) yang baru. Lebih lanjut Trianto menjelaskan dimensi belajar terdiri dari beberapa unsure yaitu: 1) penciptaan hubungan, 2) sesuatu hal (pengetahuan) yang sudah dipahami, 3) sesuatu (pengetahuan) yang baru, jadi makkna belajar di sini bukan bukan berangkat dari sesuatu yang benar-benar belum diketahui (nol), tetapi merupakan keterkaitan dari dua pengetahuan yang sudah ada dengan pengetahuan baru. ${ }^{4}$

W.S. Winkel menjelaskan bahwa belajar adalah suatu aktivitas mental atau psikis yang berlangsung dan interaksi aktif dengan lingkungan, yang menghasilkan perubahan dalam pengetahuan pemahaman, keterampilan dan nilai sikap. ${ }^{5}$ Senada dengan yang disampaikan Slameto " belajar adalah suatu proses usaha yang dilakukan individu untuk memperoleh suatu perubahan tingkah laku yang baru secara keseluruhan, sebagai hasil pengalaman individu itu sendiri dalam interaksi dengan lingkungannya."6

Belajar dapat juga didefenisikan sebagai suatu proses dimana suatu organisasi berubah perilakunya sebagai akibat pengalaman dikemukakan oleh Gagne dalam Dahar. Kegiatan belajar tersebut dapat dihayati (dialami) oleh orang yang sedang belajar. Kegiatan belajar ini juga dapat diamati oleh orang lain. Belajar dihasilkan dari pengalaman dengan lingkungan yang di dalamnya terjadi hubungan- hubungan antara stimulus-stimulus dan respon-respon. Belajar merupakan salah satu kebutuhan hidup manusia yang vital dalam usahanya untuk

\footnotetext{
${ }^{4}$ Trianto, Model Pembelajaran Terpadu. (Jakarta: PT Raja Grafindo Persada,2010), hlm 15

${ }^{5}$ Winkel, Psikologi Pendidikan dan Evaluasi Belajar. (Jakarta: Gramedia,1994), hlm 20

${ }^{6}$ Slameto, Belajar dan Faktor-Faktor Yang Mempengaruhinya, (Jakarta:PT Rineka Cipta,2006), hlm 2
} 
mencapai hidup dan mengembangkan dirinya dalam kehidupan bermasyarakat dan bernegara. Tanpa belajar manusia akan mengalami kesulitan dalam menyesuaikan diri dengan lingkungannya dan tuntutan hidup, kehidupan dan penghidupan yang senantiasa berubah. ${ }^{7}$

Dari beberapa pendapat di atas tentang pengertian belajar dapat disimpulkan bahwa belajar merupakan proses yang ditandai dengan berbagai perubahan, seperti peubahan pengetahuan, pengalaman, sikap, tingkah laku, keterampilan, kecakapan, kebiasaan serta aspek-aspek lainnya pada individu.

\section{Aktivitas Belajar}

\section{a. Pengertian Aktivitas Belajar}

Aktivitas belajar adalah seluruh aktivitas siswa selama proses pembelajaran. Pada prinsipnya belajar adalah berbuat, tidak ada belajar jika tidak ada aktivitas. Itulah mengapa aktivitas merupakan prinsip yang sangat penting dalam interaksi belajar mengajar ${ }^{8}$. Menurut Hamalik, pengajaran yang efektif adalah pengajaran yang menyediakan kesempatan belajar sendiri atau melakukan aktivitas sendiri. Aktivitas siswa yang bervariasi akan menjadikan pembelajaran semakin aktif dan tidak membosankan, ${ }^{9}$ Aktivitas siswa dalam pembelajaran dapat dilihat berdasarkan keikutsertaannya dan keterlibatannya dalam memberi respon. Semakin banyak aktivitas yag dilakukan siswa, semakin terpusat pembelajaran pada siswa.

Lufri mengatakan bahwa "makin aktif siswa mengembangkan kemampuan kognitif, apektif, psikomotor melalui berinteraksi dengan guru, teman sejawat, bahan pelajaran, media pelajaran dan lingkungan maka semakin kaya dan semakin bermakna pengalaman belajar mereka”. Aktivitas yang dituntut pada siswa dapat berupa aktivitas fisik, intelektual dan emosional. Implikasi prinsip aktivitas belajar menuntut keterlibatan langsung siswa dalam proses pembelajaran. Guru

\footnotetext{
${ }^{7}$ Dahar, Teori-Teori Belajar dan Pembelajaran, (Bandung:Erlangga,2006), hlm 2-3

${ }^{8}$ Sardiman A. M. Interaksi dan Motivasi Belajar Mengajar. Jakarta. PT. Raja Gravindo Persada. 2001. Hal 95

${ }^{9}$ Hamalik Oemar. Perencanaan Pengajaran berdasarkan Pendekatan Sistem. Jakarta Bumi Aksara. 2008. Hal 171
} 
memberi kesempatan belajar bagi siswa melaksanakan implikasi prinsip keaktipan $^{10}$.

Kegiatan belajar (aktivitas) siswa di bagi ke dalam 8 kelompok yaitu.

1. Kegiatan visual: membaca, melihat gambar, mengamati eksperimen, mengamati demonstrasi dan pameran, mengamati orang lain bekerja atau bermain.

2. Kegiatan lisan (oral): mengemukakan suatu fakta atau prinsip menghubungkan sesuatu kejadian, mengajukan pertanyaan, memberi saran, mengemukakan pendapat, wawancara, diskusi dan interupsi.

3. Kegiatan medengarkan: mendengarkan penyajian bahan, mendengarkan percakapan atau diskusi kelompok, mendengarkan permaianan, mendengarkan radio.

4. Kegiatan menulis: menulis cerita, menulis laporan, memeriksa karangan, bahan-bahan copy, membuat out line atau rangkuman, mengerjakan tes, mengisi angket

5. Kegiatan menggambar: menggambar, membuat grafik, char, diagram, peta dan pola.

6. Kegiatan motorik: melakukan percobaan, memilih alat-alat, melaksanakan pameran, membuat model, menyelenggarakan permainan, menari, berkebun.

7. Kegiatan mental: merenung, mengingat, memecahkan masalah, menganalisis faktor-faktor, melihat hubungan, membuat keputusan.

8. Kegiatan emosional: minat, membedakan, berani, tenang, dan lain-lain ${ }^{11}$.

Dari uraian yang telah dikemukakan, dapat disimpulkan bahwa dalam belajar siswa dituntut untuk terlibat aktif selama proses pembelajaran yang sedang berlangsung. Selama pembelajaran banyak aktivitas yang dapat dilakukan oleh siswa. Jika siswa dapat terlibat aktif, maka proses pembelajaran dapat berjalan dengan optimal sehingga tujuan pembelajaran dapat tercapai. Dalam proses pembelajaran, aktivitas tersebut saling mendukung dan melengkapi sehingga dapat membantu siswa dalam memahami konsep secara menyeluruh.

10 Lufri. Strategi Pengembangan Pembelajaran: teori, Praktik, dan Penelitian. Padang.UNP Press. 2007. Hal 20

${ }^{11}$ Hamalik Oemar. Perencanaan Pengajaran berdasarkan Pendekatan Sistem. Jakarta Bumi Aksara. 2008. Hal 172 
Dari proses belajar siswa tidak terlepas dari situasi yang menentukan aktivitas apa yang akan dilakukan dalam rangka belajar. Jadi aktivitas adalah kegiatan yang dilakukan dalam menghasilkan suatu hasil. Dalam proses belajar ada beberapa aktivitas belajar yang dilakukan sebagaimana yang dikemukakan oleh Syaiful Bahri Djamarah, “(1) mendengarkan, (2) memandang, (3) meraba, membau, dan mencicip/mengecap, (4) menulis atau mencatat, (5) membaca, (6) membuat ikhtisar atau ringkasan dan menggarisbawahi, (7) Mengamati tabeltabel, diagram-diagram dan bagan-bagan, (8) menyusun paper atau kertas kerja, (9) mengingat, (10) latihan atau praktek."

1. Mendengarkan

Mendengarkan adalah salah satu aktivitas belajar. Setiap yang belajar di sekolah pasti ada aktivitas mendengarkan. Ketika seorang guru mengajar dengan menggunakan metode ceramah, maka siswa akan mendengarkan penjelasan dari guru.

2. Memandang

Siswa memandang kegiatan proses belajar mengajar yang sedang berlangsung untuk melihat kegiatan guru yang sedang mengajarkan suatu materi pelajaran atau penjelasan yang berkaitan dengan materi.

3. Meraba, membau, dan mencicip/mengecap

Meraba, membau, dan mencicip/mengecap merupakan suatu aktivitas yang dilakukan untuk memperoleh perubahan tingkah laku siswa dalam proses belajar mengajar.

4. Menulis atau mencatat

Siswa akan selalu mencatat apa yang telah dijelaskan oleh guru dengan cara lisan maupun tulisan untuk memperoleh atau menghasilkan tujuan dari belajar.

5. Membaca

Aktivitas ini yang paling sering lakukan, karena membaca ini diharus membaca buku pelajaran tapi juga bisa berbagai bahan bacaan yang dapat memperoleh tingkah laku dari hasil belajar.

6. Membuat ikhtisar atau ringkasan dan menggarisbawahi 
Untuk lebih memahami suatu materi atau pelajaran perlu diadakan suatu ikhtisar atau ringkasan sehingga lebih mudah memahami materi yang sedang dipelajari.

7. Mengamati tabel-tabel, diagram-diagram dan bagan-bagan

Kadangkala tulisan diperjelas dengan tabel-tabel, diagram atau bagan sehingga lebih mudah memahaminya dan mengambil suatu intisari dari bahan tersebut.

8. Menyusun paper atau kertas kerja

Untuk menghasilkan suatu paper atau kertas kerja diperlukan suatu pemahaman yang lebih mendalam akan materi yang akan disusun, sehingga akan lebih memahami bahan yang diajarkan oleh guru.

9. Mengingat

Mengingat adalah aktivitas yang dilakukan untuk menghafalkan bahan pelajaran berupa dalil, kaidah, pengertian dan rumus.

10. Latihan atau praktek

Untuk memahami suatu rumus akan lebih mudah memahami dengan latihan atau praktek langsung. ${ }^{12}$

\section{Pembelajaran kooperatif}

Menurut Slavin pembelajaran kooperatif merupakan bentuk pembelajaran yang didasarkan pada pemahaman konstruktivisme, yaitu siswa akan lebih mudah menemukan dan memahami materi pelajaran yang sulit apabila mereka dapat saling mendiskusikan bersama dengan temannya ${ }^{13}$. Lie mengatakan Pembelajaran kooperatif mengacu pada metode pengajaran dimana siswa bekerja dalam kelompok kecil yang saling membentu dalam belajar. System pembelajaran kooperatif adalah system pembelajaran yang memberikan kesempatan kepada anak didik untuk bekerjasama dengan sesama siswa dalam tugas-tugas terstruktur dalam sebuah tim atau kelompok kecil ${ }^{14}$

Dalam pembelajaran kooperatif siswa belajar bersama dalam kelompokkelompok kecil yang saling membantu satu sama lain. Kelas disusun dalam kelompok 4-5 siswa dengan kemampuan yang heterogen. Maksud dari kelompok

\footnotetext{
${ }^{12}$ Syaiful, Bahri. Strategi Belajar Mengajar. (Jakarta: Rineka Cipta. 2013) hlm 38.

${ }^{13}$ Slavin, Cooperstive Learning. (Massachuset: Ally and Bacon. 1995) hlm 43

${ }^{14}$ Lie, Anita. Cooperative Learning. ( Jakarta: Grasindo. 2004) hlm 12
} 
yang heterogen adalah terdiri dari campuran siswa, jenis kelamin, asal dan tingkat kemampuan. Kebanyakan pembelajaran yang menggunakan model kooperatif memiliki cirri-ciri sebagai berikut:

1. Siswa bekerja dalam kelompok secara kooperatif untuk menuntaskan materi belajarnya.

2. Kelompok dibentuk dari siswa yang memiliki kemampuan tinggi, sedang dan rendah.

3. Lebih berorientasi pada keberhasilan kelompok. ${ }^{15}$

Langkah-langkah Pembelajaran Kooperatif

Trianto mengemukakan enam langkah utama atau tahapan di dalam pelajaran yang menggunakan pembelajaran kooperatif dapat dilihat pada Tabel $1:{ }^{16}$

Tabel 1. Langkah utama pembelajaran kooperatif

\begin{tabular}{|l|l|}
\hline Fase & Tingkah Laku Guru \\
\hline $\begin{array}{l}\text { Fase 1 } \\
\text { Menyampaikan tujuan dan }\end{array}$ & $\begin{array}{l}\text { Guru menyampaikan semua tujuan pelajaran } \\
\text { yang ingin dicapai pada pelajaran tersebut dan } \\
\text { memotivasi siswa belajar }\end{array}$ \\
\hline $\begin{array}{l}\text { Fase 2 } \\
\text { Menyajikan informasi }\end{array}$ & $\begin{array}{l}\text { Guru menyajikan informasi kepada siswa } \\
\text { dengan jalan demonstrasi atau lewat bahan } \\
\text { bacaan }\end{array}$ \\
\hline $\begin{array}{l}\text { Fase 3 } \\
\text { Mengorganiasikan siswa ke } \\
\text { dalam kelompok kooperatif }\end{array}$ & $\begin{array}{l}\text { Guru menjelaskan kepada siswa bagaimana } \\
\text { caranya membentuk kelompok belajar dan } \\
\text { membantu setiap kelompok agar melakukan } \\
\text { transisi secara efisien. }\end{array}$ \\
\hline $\begin{array}{l}\text { Fase 4 } \\
\text { Membimbing } \\
\text { bekerja dan belajar }\end{array}$ & $\begin{array}{l}\text { Guru membimbing kelompok-kelompok } \\
\text { belajar pada saat mereka mengerjakan tugas } \\
\text { mereka }\end{array}$ \\
\hline $\begin{array}{l}\text { Fase 5 } \\
\text { Evaluasi }\end{array}$ & $\begin{array}{l}\text { Guru mengevaluasi hasil belajar tentang } \\
\text { materi yang telah dipelajari atau masing- }\end{array}$ \\
\hline
\end{tabular}

${ }^{15}$ Ibrahim, Muslimin. Pembelajaran Kooperatif. ( Surabaya: UNESA University Press. 2002 ) hlm 12

${ }^{16}$ Trianto. Model Pembelajaran Terpadu. (Jakarta: PT. Bumi Aksara. 2010) hlm 66 


\begin{tabular}{|l|l|}
\hline & $\begin{array}{l}\text { masing kelompok mempresentasikan hasil } \\
\text { kerjanya. }\end{array}$ \\
\hline Fase 6 & $\begin{array}{l}\text { Guru mencari cara-cara untuk menghargai } \\
\text { Memberikan penghargaan } \\
\text { baik upaya maupun hasil belajar individu dan } \\
\text { kelompok. }\end{array}$ \\
\hline
\end{tabular}

Dari beberapa uraian di atas dapat disimpulkan bahwa pembelajaran kooperetif adalah pembelajaran yang melibatkan langsung siswa dengan berdiskusi kelompok untuk memecahkan permasalahan materi yang akan dibahas untuk tercapaianya tujuan pembelajaran.

\section{Model Discovery Learning}

Berdasarkan proses pembelajaran, di dalam PPRI No. 32 Tahun 2013 tentang SNP, pasal 19 ayat (1) dinyatakan bahwa proses pembelajaran pada satuan pendidikan diselenggarakan secara interaktif, inspiratif, menyenangkan, menantang, memotivasi peserta didik untuk berpartisipasi aktif, serta memberikan ruang yang cukup prakarsa, kreativitas, dan kemandirian sesuai dengan bakat, minat, dan perkembangan fisik serta psikologis peserta didik. Pasal 19 ayat (1) di atas mengindikasikan bahwa proses pembelajaran hendaknya lebih banyak berorientasi kepada penemuan. Menurut Paul Suparno Discovery Learning adalah model pembelajaran dimana guru memberikan kebebasan siswa untuk menemukan sesuatu sendiri karena dengan menemukan sendiri siswa dapat lebih mengerti secara mendalam. ${ }^{17}$

Menurut Nur pembelajaran dengan penemuan (Discovery Learning) merupakan suatu komponen penting dalam pendekatan konstruktivis yang telah memiliki sejarah panjang dalam dunia pendidikan. Ide pembelajaran penemuan (Discovery Learning) muncul dari keinginan untuk memberi rasa senang kepada siswa dalam "menemukan” sesuatu oleh mereka sendiri dengan mengikuti jejak para ilmuwan. Pada intinya, pembelajaran menekankan pada pengalaman nyata. ${ }^{18}$

\footnotetext{
${ }^{17}$ Suparno, Metodologi Pembelajaran Fisika Konstruktivistik dan Menyenangkan, (Yogyakarta:Universitas Sanata Darma,2006) hlm 72

${ }_{18}$ Muhammad Nur, Pendekatan Discovery dalam Pembelajaran (Yogyakarta:Paradigma) hlm 50
} 
Ada beberapa keuntungan dari penggunaan Discovery Learning, menurut Bruner dalam Paul Suparno antara lain sebagai berikut, (a) menggembangkan potensi intelektual, (b) mengembangkan motivasi intrinsik, (c) belajar menemukan sesuatu, (d) ingatan lebih tahan lama, (e) Discovery juga menimbulkan keingintahuan siswa dan memotivasi siswa untuk terus berusaha menemukan sesuatu sampai ketemu, dan (f) melatih keterampilan memecahkan masalah persoalan sendiri dan melatih siswa untuk dapat mengumpulkan dan menganalisis data sendiri. ${ }^{19}$

Metode mengajar yang biasa digunakan guru dalan model ini antara lain metode diskusi dan pemberian tugas. Diskusi untuk memecahkan permasalahan dilakukan oleh sekelompok kecil siswa ( antara 3-5 orang) dengan arahan dan bimbingan guru. Kegiatan ini dilaksanakan pada saat tatap muka atau pada saat kegiatan terjadwal, dengan demikian model Discovery Learning ini menunjukkan komunikasi yang digunakan bukan komunikasi satu arah. ${ }^{20}$

Muhibbin Syah mengemukakan secara garis besar bahwa prosedur pembelajaran berdasarkan Discovery Learning sebagai berikut, (1) Stimulasi , (2) Identifikasi Masalah , (3) Pengumpulan Data, (4) Pengolahan Data, (5) Verification, (6) Generalization. ${ }^{21}$ Tahap-tahap pembelajaran Discovery Learning dapat dilihat pada Tabel 2.

Tabel 2. Tahap-Tahap Pembelajaran Discovery Learning

\begin{tabular}{|l|l|l|}
\hline No & Tahap-tahap & Kegiatan Guru \\
\hline 1 & 2 & 3 \\
\hline 1 & Stimulasi & $\begin{array}{l}\text { Guru memulai kegiatan pembelajaran dengan } \\
\text { mengajukan pertanyaan kepada siswa yang } \\
\text { mengarah kepada persiapan pemecahan masalah }\end{array}$ \\
\hline 2 & $\begin{array}{l}\text { Identifikasi } \\
\text { Masalah }\end{array}$ & $\begin{array}{l}\text { Guru memberi kesempatan kepada siswa untuk } \\
\text { mengidentifikasi sebanyak mungkin masalah- }\end{array}$ \\
\hline
\end{tabular}

${ }^{19}$ Ibid. hlm 75

${ }^{20}$ Ahmad Sabri. Strategi Belajar Mengajar \& Mikro Teaching. ( Padang: Quantun Teaching, 2007 ) hlm 12

${ }^{21}$ Muhibbin Syah, Psikologi Belajar (Jakarta:PT. Raja Grapindo Persada, 2008), hlm 244 


\begin{tabular}{|l|l|l|}
\hline & & $\begin{array}{l}\text { masalah yang timbul kemudian dirumuskan dalam } \\
\text { bentuk hipotesis }\end{array}$ \\
\hline 3 & $\begin{array}{l}\text { Mengumpulkan } \\
\text { Data }\end{array}$ & $\begin{array}{l}\text { Guru memberikan kesempatan kepada siswa } \\
\text { mengumpulkan informasi untuk membuktikan benar } \\
\text { atau tidaknya hipotesis }\end{array}$ \\
\hline 4 & $\begin{array}{l}\text { Pengolahan } \\
\text { data }\end{array}$ & $\begin{array}{l}\text { Guru memberikan kesempatan kepada siswa untuk } \\
\text { mengolah data yang telah mereka dapat }\end{array}$ \\
\hline 5 & Verification & $\begin{array}{l}\text { Guru memeriksa dengan cermat untuk membuktikan } \\
\text { hipotesis dengan hasil data yang diperoleh tadi }\end{array}$ \\
\hline 6 & Generalization & Siswa menarik kesimpulan dari hasil yang diperoleh \\
\hline
\end{tabular}

(Sumber: Muhibbin Syah)

Berdasarkan Tabel 3 melalui tahap-tahap pada model Discovery Learning siswa diharapkan dapat mampu memahami penerapan dari model Discovery Learning yang dilaksanakan dalam pembelajaran. Tahap-tahap yang telah dilakukan siswa akan mempermudah siswa dalam memahami materi pelajaran yang sedang disajikan oleh guru, dengan demikian pelaksanaan Discovery Learning dapat digunakan sebagai alternatif dalam pembelajaran.

Berdasarkan pendapat di atas dapat disimpulkan bahwa model Discovery sengaja dirancang untuk meningkatkan keaktifan siswa yang lebih besar, berorientasi pada proses, untuk menemukan sendiri informasi yang diperlukan untuk mencapai tujuan instruksional. Dengan demikian model Discovery berorientasi pada proses dan hasil secara bersama-sama. Kegiatan pembelajaran semacam ini menjadikan siswa aktif dalam proses pembelajaran, guru hanya berperan sebagai fasilitator untuk mengatur jalannya pembelajaran. Proses pembelajaran yang demikian membawa dampak positif pada pengembangan kreativitas berpikir siswa.

\section{HASIL PENELITIAN}

1. Penerapan model Discovery Leraning pada mata pelajaran Sejarah Kebudayaan Islam di MTs. Muhammadiyah 22 Padangsidimpuan. 
Berdasarkan hasil observasi peneliti dengan Ibu Nurhajji Sijabat, S.Ag ${ }^{22}$ dari hasil wawancara, pengumpualan data dan pengamatan dokumentasi RPP dan LKS yang sudah diterapkan Guru dalam proses pembelajaran pada mata Pelajaran Sejarah Kebudayaan Islam. Guru belum menerapkan model belajar Discovery learning dengan metode yang tepat atau cenderung kepada model pembelajaran ceramah, hal ini bias di lihat dari rancangan RPP, LKS dan Media pembelajaran yang kurang kreatif. Contohnya dalam pemberian stimulisasi kepada siswa, Guru lebih cenderung menyampaikan pertanyaan dengan lisan padahal sangat banyak media yang tersedian yang bisa dimanfaatkan untuk proses pembelajaran yang lebih aktif, kreatif, interaktif meanantang dan menyenangkan. Yang sesuai dengan tujuan Model Pembelajaran Discovery Learning yaitu model pembelajaran dimana guru memberikan kebebasan siswa untuk menemukan sesuatu sendiri karena dengan menemukan sendiri siswa dapat lebih mengerti secara mendalam. Serta sesuai berdasarkan proses pembelajaran, di dalam PPRI No. 32 Tahun 2013 tentang SNP, pasal 19 ayat (1) dinyatakan bahwa proses pembelajaran pada satuan pendidikan diselenggarakan secara interaktif, inspiratif, menyenangkan, menantang, memotivasi peserta didik untuk berpartisipasi aktif, serta memberikan ruang yang cukup prakarsa, kreativitas, dan kemandirian sesuai dengan bakat, minat, dan perkembangan fisik serta psikologis peserta didik. Dalam observasi ini peneliti memberikan saran dan masukan kepada Guru mengenai Model pembelajran Discovery Learning untuk diterapkan agar terlaksananya penerapan model Discovery Learning yang tepat pada proses pembelajaran dan mengetahui tingkat hasil belajar siswa setelah proses pembelajaran. Berikut ini persiapan yang dirancang guru, yaitu:

\section{Penerapan Discovery Learning dapat mengaktifkan siswa dalam belajar Sejarah kebudayaan Islam di MTs. Muhammadiyah 22 Padangsidimpuan}

a. Aktivitas siswa.

Proess pembelajaran melalui penerapan model Discovery Learning dapat mengaktifkan siswa kelas VII MTs. Muhammadiyah 22 Padangsidimpuan.

\footnotetext{
${ }^{22}$ Wawancara pada tanggal 12 September 2017 dengan, Guru mata Peelajaran sejarah kebudayaan Islam di MTs. M uhammadiyah 22 Padangsidimpuan
} 
Dengan menggunakan model Pembelajaran ini Motivasi siswa lebih terpacu. Keaktifan dan kreativitasnya semakin bertambah dengan system pembelajaran yang ada dalam konsep Discovery Learning. Siswa semakin aktif, mau bermusyawarah dan pandai menyampaikan pendapat. Hal ini dapat dilihat pada hasil observasi yang peneliti lakukan pada saat pembelajaran. Hasil observasi tersebut dapat dilihat pada Tabel 3 .

Tabel 3. Data Aktivitas Siswa Kelas VII MTs. Muhammadiyah 22 Padangsidimpuan.

\begin{tabular}{|c|c|c|c|c|c|c|c|c|c|c|}
\hline \multirow[t]{2}{*}{ No } & \multirow[t]{2}{*}{ Nama Siswa } & \multicolumn{6}{|c|}{ Aktivitas Siswa } & \multirow{2}{*}{$\begin{array}{l}\text { Jlh } \\
\text { skor }\end{array}$} & \multirow[t]{2}{*}{ Nilai } & \multirow[t]{2}{*}{ Kriteria } \\
\hline & & A & B & $\mathrm{C}$ & $\mathrm{D}$ & $\mathrm{E}$ & $\mathrm{F}$ & & & \\
\hline 1 & Aditiya Putra Arifin & 2 & 3 & 3 & 3 & 3 & 3 & 17 & 94 & Aktif \\
\hline 2 & Ahmad Fauzi Nst & 3 & 3 & 3 & 3 & 2 & 3 & 17 & 94 & Aktif \\
\hline 3 & Aisyah Sumaiyah & 2 & 2 & 3 & 3 & 3 & 3 & 16 & 89 & Aktif \\
\hline 4 & Arini Amelia & 3 & 3 & 3 & 3 & 2 & 2 & 17 & 94 & Aktif \\
\hline 5 & Chealse Aprisa Smt & 3 & 2 & 3 & 3 & 3 & 3 & 17 & 94 & Aktif \\
\hline 6 & Hilda Dwi R. Hrp & 3 & 2 & 2 & 3 & 2 & 3 & 15 & 83 & Aktif \\
\hline 7 & Kelvin Abdullah & 3 & 2 & 3 & 2 & 3 & 3 & 16 & 89 & Aktif \\
\hline 8 & Muhammad Akhir & 2 & 2 & 3 & 3 & 2 & 3 & 15 & 83 & Aktif \\
\hline 9 & Nuraisah Sihombing & 3 & 3 & 3 & 2 & 3 & 3 & 17 & 94 & Aktif \\
\hline 10 & Nurhalimah & 3 & 2 & 3 & 3 & 3 & 3 & 17 & 94 & Aktif \\
\hline 11 & Fadly Riski R & 2 & 3 & 3 & 3 & 3 & 3 & 17 & 94 & Aktif \\
\hline 12 & Putri Ramadhani & 3 & 3 & 3 & 3 & 3 & 2 & 17 & 94 & Aktif \\
\hline 13 & Rusman Zuhdi & 2 & 2 & 2 & 3 & 3 & 3 & 15 & 83 & Aktif \\
\hline 14 & Rafli Harahap & 3 & 2 & 2 & 3 & 3 & 3 & 16 & 89 & Aktif \\
\hline 15 & Riska Ramadhani & 3 & 3 & 3 & 3 & 2 & 3 & 17 & 94 & Aktif \\
\hline 16 & Riski Dodi Saputra & 3 & 3 & 2 & 2 & 3 & 3 & 16 & 89 & Aktif \\
\hline 37 & Safrijal Pasaribu & 2 & 2 & 2 & 2 & 3 & 3 & 14 & 78 & Kurang Aktif \\
\hline 18 & Sarah Rahmaito & 2 & 3 & 3 & 2 & 3 & 3 & 16 & 89 & Aktif \\
\hline 19 & Ummi Parida Nst & 3 & 3 & 3 & 3 & 3 & 3 & 18 & 100 & Aktif \\
\hline 20 & Yayang Anugrah & 3 & 2 & 2 & 3 & 3 & 3 & 16 & 89 & Aktif \\
\hline
\end{tabular}




\begin{tabular}{|c|c|c|c|c|c|c|c|c|c|c|}
\hline \multirow[t]{2}{*}{ No } & \multirow[t]{2}{*}{ Nama Siswa } & \multicolumn{6}{|c|}{ Aktivitas Siswa } & \multirow{2}{*}{$\begin{array}{l}\text { Jlh } \\
\text { skor }\end{array}$} & \multirow[t]{2}{*}{ Nilai } & \multirow[t]{2}{*}{ Kriteria } \\
\hline & & A & B & $\mathrm{C}$ & $\mathrm{D}$ & $\mathrm{E}$ & $\mathrm{F}$ & & & \\
\hline 21 & Zahra Tsabita & 3 & 3 & 2 & 3 & 3 & 3 & 17 & 94 & Aktif \\
\hline 22 & Muhammad Andry & 3 & 2 & 2 & 3 & 3 & 3 & 16 & 89 & Aktif \\
\hline 23 & Raja Oloansyah & 2 & 2 & 3 & 2 & 2 & 2 & 13 & 72 & Kurang Aktif \\
\hline 24 & Listi Amaliyah & 3 & 3 & 3 & 2 & 3 & 3 & 17 & 94 & Aktif \\
\hline
\end{tabular}

\section{Keterangan:}

A : Menjawab pertanyaan stimulasi

B : Melakukan diskusi kelompok

C : Mempertasikan hasil diskusi

D : Memberikan tanggapan-tanggapan hasil diskusi

E : Mengajukan pertanyaan yang berkaitan dengan materi pelajaran

F : membuat kesimpulan

\section{Tabel 4. Rubrik Penilaian Aktivitas Siswa}

\begin{tabular}{|l|l|l|}
\hline No & Aspek yag dinilai & Rubrik \\
\hline 1 & $\begin{array}{l}\text { A: } \begin{array}{l}\text { Menjawab } \\
\text { pertanyaan stimulasi } \\
\text { dari guru ( stimulasi) }\end{array} \\
\text { guru }\end{array}$ & $\begin{array}{l}\text { siswa menjawab pertanyaan stimulasi dari } \\
\text { siswa kurang mampu menjawab pertanyaan } \\
\text { stimulasi dari guru } \\
1=\text { siswa tidak mampu menjawab pertanyaan } \\
\text { stimulasi dari guru }\end{array}$ \\
\hline 2 & $\begin{array}{l}\text { B: Bekerja dan } \\
\text { berdiskusi dengan } \\
\text { teman kelompoknya } \\
\text { identifikasi masalah, } \\
\text { mengumpulkan data } \\
\text { dan mengolah data) }\end{array}$ & $\begin{array}{l}\text { kelompoknya untuk menyelesaikan LKS } \\
2=\text { siswa bekerja tapi tidak berdiskusi dengan } \\
\text { kelompoknya untuk menyelesaikan LKS ataupun } \\
\text { sebaliknya } \\
1=\text { siswa tidak bekerja dan tidak berdiskusi } \\
\text { dengan kelompoknya untuk mengerjakan LKS }\end{array}$ \\
\hline 3 & $\begin{array}{l}\text { C: Mempersentasikan } \\
\text { hasil diskusi (verifikasi) }\end{array}$ & $\begin{array}{l}3=\text { siswa mempersentaikan hasil diskusi dengan } \\
\text { benar dan jelas }\end{array}$ \\
\hline
\end{tabular}




\begin{tabular}{|c|c|c|}
\hline & & $\begin{array}{l}2=\text { siswa mempersentasikan hasil diskusi dengan } \\
\text { kurang benar dan kurang benar } \\
1=\text { siswa tidak mempersentasikan hasil diskusi }\end{array}$ \\
\hline 4 & $\begin{array}{lr}\text { D: } & \text { Memberikan } \\
\text { tanggapan } & \text { terhaap } \\
\text { kelompok } & \text { yang } \\
\text { persentasi (verifiksi) }\end{array}$ & $\begin{array}{l}3=\text { siswa mampu memberikan tanggapan } \\
\text { terhadap kelompok yang persentasi } \\
2=\text { siswa kurang mampu memberikan tanggapan } \\
\text { terhadap kelompok yang persentasi } \\
\text { 1= siswa tidak mampu memberikan tanggapan } \\
\text { terhadap kelompok yang persentasi }\end{array}$ \\
\hline 5 & $\begin{array}{lr}\text { E: } & \text { Mengajukan } \\
\text { pertnyaan } & \text { yang } \\
\text { berhubungan } & \text { dengan } \\
\text { materi } & \text { pelajaran } \\
\text { (verifikasi) } & \end{array}$ & $\begin{array}{l}3=\text { siswa mampu mengajukan pertanyaan yang } \\
\text { berkaitan dengan materi pelajaran } \\
2=\text { siswa kurang mampu mengajukan pertanyaan } \\
\text { yang berkaitan dengan materi pelajaran } \\
1=\text { siswa tidak mampu mengajukan pertanyaan } \\
\text { yang berkaitan dengan materi pelajaran. }\end{array}$ \\
\hline 6 & $\begin{array}{l}\mathrm{F}: \\
\text { kesimpulan }\end{array}$ & $\begin{array}{l}3=\text { siswa mampu membuat kesimpulan sesuai } \\
\text { dengan tujuan pembelajaran } \\
2=\text { siswa mampu membuat kesimpulan tapi } \\
\text { kurang sesuai dengan tujuan pembelajaran } \\
\text { 1= siswa tidak mampu membuat kesimpulan }\end{array}$ \\
\hline
\end{tabular}

Table 5. Pedoman penskoran dan penilaian

\begin{tabular}{|l|l|l|}
\hline Skor & Kriteria & Nilai \\
\hline 3 & Aktif & $80-100$ \\
\hline 2 & Kurang aktif & $60-79$ \\
\hline 1 & Tidak aktif & $<60$ \\
\hline
\end{tabular}

\section{b. Hasil Belajar}

Guru juga menilai hasil belajar siswa yang terdiri dari tiga aspek, yaitu:

1) Kognitif 
Hasil belajar kognitif merupakan hasil belajar intelektual siswa yang datanya diambil dari nilai jawaban tes tertulis di akhir pertemuan. Adapun pertanyaannya sebagai berikut:

1.Jelaskan secara singkat fase-fase mulai diangkatnya Nabi Muhammad SAW sebagai Nabi dan Rasul!

2.Jelaskan rintangan apa saja yang dihadapi Nabi Muhammad SAW sampai penduduk Mekah berbondong-bondong memeluk agama Islam dalam peristiwa fathu Makkah!

3.Sebutkan apa saja yang dapat kamu teladani dari sifat-sifat Nabi dan para sahabatnya dalam menyebarkan dan mempertahankan ajaran dan akidah Islam!

\section{Table 6. Pedoman penskoran}

\begin{tabular}{|l|l|l|}
\hline No & Jawaban & Skor \\
\hline $\mathbf{1}$ & $\begin{array}{l}\text { Diusia remaja Nabi Muhammad SAW terkenal dengan budu } \\
\text { luhur dan kemuliaan perangainya. Ia dijuluki Al-Amin artinya } \\
\text { yang sangat terpercaya. Karena itu pulalah Khadijah binti } \\
\text { khuwalid tertarik agar Nabi Muhammad SAW menjualkan } \\
\text { dagangannya ke Syam. Perdagangan Nabi di Syam } \\
\text { menghasilkan keuntungan yang banyak kerena kejujuran dan } \\
\text { keuletannya. Hal itu pulalah yang menrik Siti Khadijah untuk } \\
\text { melamar Nabi agar menikahi dirinya ketika diusia 25 tahun } \\
\text { dan Siti Khadijah berusia 40 tahun. menjelang usia 40 tahun } \\
\text { beliu memilih Gua hira sebagai tempat untuk berkhalwat. } \\
\text { Setelah enam bulan berkhalwat atau mengasingkan diri di } \\
\text { Gua Hira beliau didatangi Malaikat Jibril utusan Allah } \\
\text { menyampaikan wahyuNya yang pertama yaitu surah Al-Alaq } \\
\text { ayat 1-5. Peristiwa tersebut menjadi awal diangkatnya Nabi } \\
\text { Muhammad menjadi Rasul Allah berdarkan ucapan Malaikat } \\
\text { Jibril, “ gembiralah ya Muhammad! Saya Jibril dan engkau } \\
\text { adalah Rasul Allah kepada ummat ini. }\end{array}$ & \\
\hline $\mathbf{2}$ & $\begin{array}{l}\text { Rintangan yang paling besar justru datang dari kerabat dan } \\
\text { kaumnya sendiri. Mereka menetang keras seruan Tuhan yanh }\end{array}$ & 25 \\
\hline
\end{tabular}




\begin{tabular}{|l|l|l|}
\hline & $\begin{array}{l}\text { disampaikan Nabi Muhammad SAW. Banyak pengikut Nabi } \\
\text { yang menjadi korban penyiksaan dan pembunuhan, } \\
\text { diasingkan dan diboikot perekonomiannya. Persekongkolan } \\
\text { penduduk makkah yang dipimpin oleh Abu Lahab dan Abu } \\
\text { Jahal untuk membunuh Nabi Muhammad SAW. }\end{array}$ & \\
\hline $\mathbf{3}$ & $\begin{array}{l}\text { - Memiliki akidah ( keyakinan ) yang kuat } \\
\text { - Bersikap tegas menolak kekufuran, kemusyrikan, dan }\end{array}$ & $\mathbf{2 5}$ \\
- kemaksiatan. & Sabar dalam menghadapi ujian dan cobaan \\
- Memiliki rasa tanggung jawab terhadap tugas dan amanat & $\mathbf{1 0 0}$ \\
\hline Total skor & \\
\hline
\end{tabular}

Table 7. Rubrik

\begin{tabular}{|l|l|l|}
\hline No & Keterangan & Skor \\
\hline 1 & Apabila jawaban benar dan lengkap & 50 \\
& Apabila jawaban benar tapi tidak lengkap & 25 \\
& Apabila jawaban tidak benar dan tidak lengkap & 0 \\
\hline 2 & Jika jawaban benar dan lengkap & 25 \\
& Jika jawaban benar tapi kurang lengkap & 15 \\
\hline 3 & Jika jawaban salah & 0 \\
\hline & Jika jawaban memiliki 4 poin yang benar & 25 \\
& Jika jawaban memiliki 3 poin yang benar & 20 \\
& Jika jawaban memilliki 2 poin yang benar & 15 \\
& Jika jawaban memiliki 1 poin yang benar & 10 \\
\hline & Jika jawaban semua salah & 0 \\
\hline
\end{tabular}

Table 8. Data hasil belajar kognitif dengan test tertulis sebagai berikut:

\begin{tabular}{|l|l|l|l|}
\hline No & Nama Siswa & Nilai & Ketuntasan \\
\hline 1 & Aditiya Putra Arifin & 80 & Tuntas \\
\hline 2 & Ahmad Fauzi Nasution & 80 & Tuntas \\
\hline
\end{tabular}




\begin{tabular}{|c|c|c|c|}
\hline No & Nama Siswa & Nilai & Ketuntasan \\
\hline 3 & Aisyah Sumaiyah & 85 & Tuntas \\
\hline 4 & Arini Amelia & 80 & Tuntas \\
\hline 5 & Chealse Aprisa Smtp & 90 & Tuntas \\
\hline 6 & Hilda Dwi R. Harahap & 90 & Tuntas \\
\hline 7 & Kelvin Abdullah & 75 & Tuntas \\
\hline 8 & Muhammad Akhir Lubis & 80 & Tuntas \\
\hline 9 & Nuraisah Sihombing & 80 & Tuntas \\
\hline 10 & Nurhalimah & 85 & Tuntas \\
\hline 11 & Fadly Riski Ramadhan & 90 & Tuntas \\
\hline 12 & Putri Ramadhani & 85 & Tuntas \\
\hline 13 & Rusman Zuhdi & 75 & Tuntas \\
\hline 14 & Rafli Harahap & 80 & Tuntas \\
\hline 15 & Riska Ramadhani & 90 & Tuntas \\
\hline 16 & Riski Dodi Saputra & 80 & Tuntas \\
\hline 17 & Safrijal Pasaribu & 80 & Tuntas \\
\hline 18 & Sarah Rahmaito & 80 & Tuntas \\
\hline 19 & Ummi Parida Nasution & 90 & Tuntas \\
\hline 20 & Yayang Anugrah & 85 & Tuntas \\
\hline 21 & Zahra Tsabita & 85 & Tuntas \\
\hline 22 & Muhammad Andry & 80 & Tuntas \\
\hline 23 & Raja Oloansyah & 80 & Tuntas \\
\hline 24 & Listi Amaliyah & 85 & Tuntas \\
\hline
\end{tabular}

\section{2) Apektif}

Hasil belajar apektif adalah hasil belajar yang diobservasi dari sikap siswa saat proses pembelajaran. Adapun hasil yang peneliti temukan dapat dilihat pada Tabel 9.

Tabel 9. Data Hasil Belajar Apektif

\begin{tabular}{|c|c|c|c|c|c|c|c|c|c|c|}
\hline \multirow[t]{2}{*}{ No } & \multirow[t]{2}{*}{ Nama Siswa } & \multicolumn{6}{|c|}{ Sikap Siswa } & \multirow{2}{*}{$\begin{array}{l}\text { Jlh } \\
\text { skor }\end{array}$} & \multirow[t]{2}{*}{ Nilai } & \multirow[t]{2}{*}{ Kriteria } \\
\hline & & A & B & $\mathrm{C}$ & D & $\mathrm{E}$ & $\mathrm{F}$ & & & \\
\hline
\end{tabular}




\begin{tabular}{|c|c|c|c|c|c|c|c|c|c|c|}
\hline \multirow[t]{2}{*}{ No } & \multirow[t]{2}{*}{ Nama Siswa } & \multicolumn{6}{|c|}{ Sikap Siswa } & \multirow{2}{*}{$\begin{array}{l}\text { Jlh } \\
\text { skor }\end{array}$} & \multirow[t]{2}{*}{ Nilai } & \multirow[t]{2}{*}{ Kriteria } \\
\hline & & A & B & $\mathrm{C}$ & $\mathrm{D}$ & $\mathrm{E}$ & $\mathrm{F}$ & & & \\
\hline 1 & Aditiya Putra Arifin & 4 & 4 & 3 & 4 & 4 & 4 & 23 & 96 & SB \\
\hline 2 & Ahmad Fauzi Nst & 4 & 4 & 4 & 4 & 3 & 4 & 23 & 96 & SB \\
\hline 3 & Aisyah Sumaiyah & 4 & 3 & 4 & 4 & 4 & 3 & 22 & 92 & SB \\
\hline 4 & Arini Amelia & 3 & 3 & 4 & 4 & 4 & 4 & 22 & 92 & SB \\
\hline 5 & Chealse Aprisa Smt & 3 & 3 & 3 & 3 & 4 & 3 & 19 & 79 & B \\
\hline 6 & Hilda Dwi R. Hrp & 3 & 4 & 4 & 3 & 4 & 4 & 22 & 92 & SB \\
\hline 7 & Kelvin Abdullah & 3 & 3 & 3 & 2 & 2 & 3 & 16 & 67 & $\mathrm{C}$ \\
\hline 8 & Muhammad Akhir & 3 & 3 & 3 & 3 & 3 & 3 & 18 & 75 & Baik \\
\hline 9 & Nuraisah $\mathrm{S}$ & 4 & 3 & 3 & 4 & 3 & 4 & 21 & 88 & SB \\
\hline 10 & Nurhalimah & 3 & 3 & 3 & 3 & 4 & 4 & 18 & 75 & baik \\
\hline 11 & Fadly Riski R & 4 & 4 & 3 & 3 & 4 & 3 & 21 & 88 & SB \\
\hline 12 & Putri Ramadhani & 4 & 4 & 4 & 3 & 4 & 4 & 23 & 96 & SB \\
\hline 13 & Rusman Zuhdi & 3 & 4 & 3 & 3 & 3 & 4 & 20 & 83 & SB \\
\hline 14 & Rafli Harahap & 3 & 3 & 4 & 4 & 4 & 3 & 21 & 88 & SB \\
\hline 15 & Riska Ramadhani & 3 & 4 & 4 & 4 & 3 & 3 & 21 & 88 & SB \\
\hline 16 & Riski Dodi Saputra & 4 & 3 & 3 & 4 & 4 & 4 & 22 & 92 & SB \\
\hline 17 & Safrijal Pasaribu & 4 & 4 & 4 & 3 & 4 & 4 & 23 & 96 & SB \\
\hline 18 & Sarah Rahmaito & 4 & 4 & 4 & 3 & 3 & 3 & 21 & 88 & SB \\
\hline 19 & Ummi Parida Nst & 3 & 3 & 3 & 2 & 4 & 4 & 19 & 79 & B \\
\hline 20 & Yayang Anugrah & 4 & 4 & 4 & 3 & 3 & 4 & 22 & 92 & SB \\
\hline 21 & Zahra Tsabita & 4 & 4 & 4 & 3 & 4 & 3 & 22 & 92 & SB \\
\hline 22 & Muhammad Andry & 3 & 3 & 4 & 4 & 4 & 4 & 22 & 92 & SB \\
\hline 23 & Raja Oloansyah & 3 & 4 & 3 & 4 & 4 & 4 & 22 & 92 & SB \\
\hline 24 & Listi Amaliyah & 3 & 4 & 2 & 4 & 3 & 3 & 19 & 79 & B \\
\hline
\end{tabular}

Keterangan:
A: Kerja sama
B: Santun
C: Toleran
D: Responsif
E: Proaktif
F: Bijaksana 


\section{Rubrik Penilaian}

Isilah table penilaian sikap dengan menggunakan skor 1-4 dengan memperhatikan rubrik di bawah ini.

\section{Tabel 10. Rubrik Penilaian Sikap}

\begin{tabular}{|c|c|c|}
\hline No & Aspek yang Dinilai & Skor \\
\hline A & $\begin{array}{l}\text { Jika selalu melakukan kerjasama dengan baik } \\
\text { Jika sering melakukan kerjasama dengan baik } \\
\text { Jika kadang-kadang melakukan kerjasama dengan baik } \\
\text { Jika tidak melakukan kerjasama dengan baik }\end{array}$ & $\begin{array}{l}4 \\
3 \\
2 \\
1\end{array}$ \\
\hline B & $\begin{array}{l}\text { Jika saat belajar selalu menggunakan bahasa dan sikap yang } \\
\text { santun } \\
\text { Jika saat belajar sering menggunakan bahasa dan sikap yang } \\
\text { santun } \\
\text { Jika saat belajar kadang-kadang menggunakan bahasa dan sikap } \\
\text { yang santun } \\
\text { Jika saat belajar tidak pernah menggunakan bahasa dan sikap yang } \\
\text { santun }\end{array}$ & 3 \\
\hline $\mathrm{C}$ & $\begin{array}{l}\text { Jika saat diskusi selalu menunjukkan sikap toleran terhadap teman } \\
\text { sekelompoknya } \\
\text { Jika saat diskusi sering menunjukkan sikap toleran terhadap } \\
\text { teman sekelompoknya } \\
\text { Jika saat diskusi kadang-kadang menunjukkan sikap toleran } \\
\text { terhadap teman sekelompoknya } \\
\text { Jika saat diskusi tidak pernah menunjukkan sikap toleran terhadap } \\
\text { teman sekelompoknya }\end{array}$ & 3 \\
\hline $\mathrm{D}$ & $\begin{array}{l}\text { Jika saat belajar selalu menunjukkan sikap responsive terhadap } \\
\text { masalah yang dihadapi } \\
\text { Jika saat belajar sering menunjukkan sikap responsive terhadap } \\
\text { masalah yang dihadapi } \\
\text { Jika saat belajar kadang-kadang menunjukkan sikap responsive }\end{array}$ & 4 \\
\hline
\end{tabular}




\begin{tabular}{|l|l|l|}
\hline No & Aspek yang Dinilai & Skor \\
\hline & $\begin{array}{l}\text { terhadap masalah yang dihadapi } \\
\text { Jika saat belajar tidak pernah menunjukkan sikap responsive } \\
\text { terhadap masalah yang dihadapi }\end{array}$ & 1 \\
\hline E & $\begin{array}{l}\text { Jika saat belajar selalu menunjukkan sikap proaktif dalam } \\
\text { melakukan setiap kegiatan }\end{array}$ & 4 \\
Jika saat belajar sering menunjukkan sikap proaktif dalam & 3 \\
melakukan setiap kegiatan & $\begin{array}{l}\text { Jika saat belajar kadang-kadang menunjukkan sikap proaktif } \\
\text { dalam melakukan setiap kegiatan } \\
\text { melakukan setiap kegiatan }\end{array}$ & 2 \\
\hline Jika saat belajar selalu menunjukkan sikap bijaksana dalam \\
memecahkan masalah \\
$\begin{array}{l}\text { Jika saat belajar sering menunjukkan sikap bijaksana dalam } \\
\text { memecahkan masalah } \\
\text { Jika saat belajar kadang-kadang menunjukkan sikap bijaksana } \\
\text { dalam memecahkan masalah } \\
\text { Jika saat belajar tidak pernah menunjukkan sikap bijaksana dalam } \\
\text { memecahkan masalah }\end{array}$ & 2 \\
\hline
\end{tabular}

Tabel 10. Pedoman Penskoran dan Penilaian

\begin{tabular}{|l|l|}
\hline Predikat & Nilai \\
\hline Sangat Baik & $80-100$ \\
\hline Baik & $70-79$ \\
\hline Cukup & $60-69$ \\
\hline Kurang & $<60$ \\
\hline
\end{tabular}

\section{E. PENUTUP}

Berdasarkan tujuan penelitian, hasil penelitian dan pembahasan, maka penelitian yang dilaksanakan di kelas VII MTs. Muhammadiyah 22 Padangsidimpuan dapat disimpulkan sebagai berikut:

1. Penerapan model Discovery Leraning pada mata pelajaran Sejarah Kebudayaan Islam di MTs. Muhammadiyah 22 Padangsidimpuan dapat 
berjalan dengan baik sehingga hasil belajar dapat mencapai tujuan pembelajaran.

2. Penerapan Discovery Learning dapat mengaktifkan siswa dalam belajar Sejarah kebudayaan Islam di MTs. Muhammadiyah 22 Padangsidimpuan, dimana hasil aktivitas belajar siswa dapat mencapai kriteria aktif dengan jumlah yang banyak.

\section{DAFTAR PUSTAKA}

Kemendikbud, Modul Pelatihan Implementasi Kurikulum 2013, (Jakarta, Badan Pengembangan Sumber Daya Manusia Pendidikan dan Kebudayaan dan Penjamin Mutu Pendidikan,2014

Trianto, Model Pembelajaran Terpadu. Jakarta: PT Raja Grafindo Persada,2010

Winkel, Psikologi Pendidikan dan Evaluasi Belajar. Jakarta: Gramedia,1994

Slameto, Belajar dan Faktor-Faktor Yang Mempengaruhinya, Jakarta:PT Rineka Cipta,2006

Dahar, Teori-Teori Belajar dan Pembelajaran, Bandung:Erlangga,2006

Sardiman A. M. Interaksi dan Motivasi Belajar Mengajar. Jakarta. PT. Raja Gravindo Persada. 2001.

Hamalik Oemar. Perencanaan Pengajaran berdasarkan Pendekatan Sistem. Jakarta Bumi Aksara. 2008.

Lufri. Strategi Pengembangan Pembelajaran: teori, Praktik, dan Penelitian. Padang.UNP Press. 2007.

Hamalik Oemar. Perencanaan Pengajaran berdasarkan Pendekatan Sistem. Jakarta Bumi Aksara. 2008.

Syaiful, Bahri. Strategi Belajar Mengajar. Jakarta: Rineka Cipta. 2013

Slavin, Cooperstive Learning. Massachuset: Ally and Bacon. 1995

Lie, Anita. Cooperative Learning. Jakarta: Grasindo. 2004

Ibrahim, Muslimin. Pembelajaran Kooperatif. Surabaya: UNESA University Press. 2002 
Trianto. Model Pembelajaran Terpadu. (Jakarta: PT. Bumi Aksara. 2010) hlm 66

Suparno, Metodologi Pembelajaran Fisika Konstruktivistik dan Menyenangkan, Yogyakarta:Universitas Sanata Darma,2006

Muhammad Nur, Pendekatan Discovery dalam Pembelajaran Yogyakarta:Paradigma

Ahmad Sabri. Strategi Belajar Mengajar \& Mikro Teaching. Padang: Quantun Teaching, 2007

Muhibbin Syah, Psikologi Belajar Jakarta:PT. Raja Grapindo Persada, 2008 